\title{
Antiplasmodial and Antipyretic Activity and Safety Evaluation of the Methanolic Leaf Extract of Murraya exotica (L.)
}

\author{
Arnold Donkor Forkuo ${ }^{\mathbb{D}},{ }^{1}$ Kwesi Boadu Mensah ${ }^{\mathbb{D}},{ }^{1}$ Elvis Ofori Ameyaw, ${ }^{2}$ \\ Aaron Opoku Antwi ${ }^{\mathbb{D}},{ }^{1}$ Nana Kofi Kusi-Boadum, ${ }^{1}$ and Charles Ansah ${ }^{1}$ \\ ${ }^{1}$ Department of Pharmacology, Faculty of Pharmacy and Pharmaceutical Sciences, Kwame Nkrumah University of Science \\ and Technology, Kumasi, Ghana \\ ${ }^{2}$ Department of Biomedical and Forensic Sciences, School of Biological Science, College of Agriculture and Natural Sciences, \\ University of Cape Coast, Cape Coast, Ghana
}

Correspondence should be addressed to Arnold Donkor Forkuo; forkuoarnold@yahoo.com

Received 18 March 2020; Revised 19 June 2020; Accepted 20 June 2020; Published 5 August 2020

Academic Editor: Bernard Marchand

Copyright ( 92020 Arnold Donkor Forkuo et al. This is an open access article distributed under the Creative Commons Attribution License, which permits unrestricted use, distribution, and reproduction in any medium, provided the original work is properly cited.

\begin{abstract}
Background. The increasing mortality and morbidity of malaria in Africa coupled with the recent reports of antimalarial drug resistance reinforces the need for novel antimalarial agents from natural plant products with folkloric use for the disease. Murraya exotica (L.) (Rutaceae) is widely used as an ornamental plant used indigenously to treat fever, cough, and infectious wounds and eliminate pain from injury and trauma. This study was conducted to evaluate extracts of the leaves of Murraya exotica (L.) (Rutaceae) for its safety and antipyretic and antimalarial activity in rodent models. Method. In this study, the Peters 4-day suppressive and curative test in Plasmodium berghei-infected mice was used to demonstrate the antiplasmodial activity of the methanolic leaf extract of Murraya exotica (L.) (MEE). The study also evaluated the subacute toxicity study and the antipyretic activity of MEE on baker's yeast-induced hyperthermia in rodent models. Results. Murraya exotica (L.) extract demonstrated curative antimalarial activity, with a percentage suppression of $45.84,64.32 \pm 0.33,56.74 \pm 2.16$, and $64.61 \pm 0.67$ at doses of $50,100,300$, and $600 \mathrm{mg} / \mathrm{kg}$, respectively. In the Peters 4-day suppressive test, MEE at dose $600 \mathrm{mg} / \mathrm{kg} \mathrm{had} \mathrm{the}$ highest chemosuppression $(76.02 \pm 1.38 \%)$ compared with artesunate $(2 \mathrm{mg} / \mathrm{kg}$, p.o.) $(82.56 \pm 0.97 \%)$. Subacute oral toxicity studies in Sprague-Dawley rats documented no deaths, with no significant changes in clinical signs, organ weights, and hematological and biochemical parameters. The $\mathrm{LD}_{50}$ of MEE was estimated to be above $1000 \mathrm{mg} / \mathrm{kg}$ in Sprague-Dawley rats. All doses of MEE and paracetamol reduced pyrexia in $1 \mathrm{~h}$ and $2 \mathrm{~h}$ after their administration. The percentage reduction of rectal temperature $\left(T_{R}\right)$ for the positive control (paracetamol, $150 \mathrm{mg} / \mathrm{kg}$, p.o.) was $44.36 \%$ while the Murraya exotica extract at doses $50 \mathrm{mg} / \mathrm{kg}, 100 \mathrm{mg} / \mathrm{kg}, 300 \mathrm{mg} / \mathrm{kg}$, and $600 \mathrm{mg} / \mathrm{kg}$ recorded $67.74 \%, 40.78 \%, 66.42 \%$, and $59.42 \%$, respectively. Murraya exotica at dose $100 \mathrm{mg} / \mathrm{kg}$ exhibited significant reduction $(p<0.05)$ in baker's yeast-induced pyrexia. Conclusions. The findings in this study show the antipyretic, curative, and suppressive antiplasmodial activity as well as the safety of the methanolic leaf extract of Murraya exotica (L.) supporting its traditional use for malaria and fever.
\end{abstract}

\section{Background}

Despite several years of intense research, malaria remains a deadly worldwide disease. According to the World Health Organization [1], about 219 million cases of malaria were reported in 90 countries with 435,000 deaths in 2017. The WHO African Region was home to $92 \%$ of these malaria cases and $93 \%$ of malaria deaths. Antimalarial drug resis- tance remains a major hurdle in the global effort to eradicate malaria [2]. The persistence of this global health problem is partly attributed to the development of resistance by the limited available antimalarials. The artemisinins, though effective in the global fight against malaria, are hampered by limited supply and high cost.

While there is much need for more antimalarial agents, the drug development pipeline remains woefully thin, with 
little chemical diversity. Currently, no clinically tested alternative to the valuable artemisinins has been developed [3]. Although vaccine development could be the surest longterm control option, clinical trials are still ongoing [4].

Plant-derived compounds have played a crucial role in the discovery and development of new drug molecules for the treatment of several diseases. Medicinal plants have been used for the prevention and treatment of malaria, and the isolation of new bioactive compounds from these plants offers novel, affordable, and efficient options that could serve as primary molecules for antimalarial treatment with artemisinin and quinine being classical examples [5].

Murraya exotica (L.) (Rutaceae) is an example of a medicinal plant that has been used traditionally in the treatment of malaria [6] with no scientific credence. In southern China where the plant is actively grown, Murraya exotica (L.) (Rutaceae) has been well documented in the Pharmacopoeia of the People's Republic of China for the treatment of rheumatic arthralgia, stomachache, fever, body swelling, toothache, and pain [7]. Wu et al. [8] have demonstrated the antinociceptive and anti-inflammatory activities of $70 \%$ ethanol extracts of $M$. exotica in rat knee osteoarthritis models.

This study is aimed at evaluating the in vivo antiplasmodial, safety, and antipyretic properties of the methanolic leaf extract of Murraya exotica (L.) (Rutaceae) in rodent models.

\section{Methods}

2.1. Plant Collection and Authentication. The fresh leaves of Murraya exotica (L.) were collected in Bekwai, Ashanti region (August 2017). Dr. George Henry Sam of the Department of Herbal Medicine identified and authenticated the plant using organoleptic analysis. A voucher specimen (KNUST/H/M/2017/M007) of the leaves of Murraya exotica (L.) was kept at the herbarium of the Faculty of Pharmacy and Pharmaceutical Sciences, Kwame Nkrumah University of Science and Technology (KNUST), Kumasi, Ghana.

2.2. Extraction of Plant Material. The fresh leaves were washed and air-dried for 2 weeks under shade. The dry leaves obtained were then milled into powder with a laboratory scale mill. The powdered leaves $(2 \mathrm{~kg})$ were extracted by maceration with 101 of $70 \%$ methanol for 72 hours at room temperature and then concentrated under reduced pressure at $40^{\circ} \mathrm{C}$ into an oily mass in a rotary evaporator. The extract was further dried in a hot air oven at $40^{\circ} \mathrm{C}$ for 3 days and then kept in a refrigerator for later use. The final yield was $24.10 \%$ $(w / w)$. The crude extract obtained is subsequently referred to as Murraya exotica extract (MEE) or the extract in this study. The various concentrations of the methanolic extract were prepared in 5\% sodium carboxymethylcellulose solution for the experimental procedures.

2.3. Experimental Animals. Male Sprague-Dawley rats (125$167 \mathrm{~g})$ and ICR-strain mice (18-22 g) between 6 and 8 weeks were used. They were obtained from Noguchi Memorial Institute for Medical Research (NMIR), University of Ghana, Legon, and kept in the animal house of the Department of
Pharmacology, KNUST. The animals were housed in stainless steel cages and maintained under normal animal housing conditions. This involved the monitoring of room conditions, monitoring of animals for health problems and pregnancy, proper cage enclosure conditions, food and water levels, proper ventilation, light, temperature, and sanitation. Rats and mice were fed a commercial pellet diet and granted access to clean water.

2.4. Rodent Parasite. The species of malaria parasite used to infect the mice was Plasmodium berghei NK 65 and was obtained from Noguchi Memorial Institute for Medical Research. The parasites were kept alive by intraperitoneal passage in mice after $\geq 5 \%$ parasitemia has been established.

2.5. Chemicals and Reagents. Methanol, ethanol, ferric chloride $\left(\mathrm{FeCl}_{3}\right)$, hydrochloric acid $(\mathrm{HCl})$, Dragendorff's reagent, sulphuric acid $\left(\mathrm{H}_{2} \mathrm{SO}_{4}\right)$, sodium hydroxide $(\mathrm{NaOH})$, chloroform, acetic anhydride, sodium carboxymethylcellulose, 10\% formalin, and $10 \%$ Giemsa. All the chemicals used were of analytical grade.

2.6. Phytochemical Screening of Murraya exotica Extract. Standard laboratory methods described by Vaghasiya et al. [9] were used in the phytochemical screening of secondary metabolites of the methanol extract of the leaves of Murraya exotica (MEE).

2.7. Peters 4-Day Suppressive Test. The in vivo antimalarial activity of Murraya exotica extract (MEE) was assessed using the 4-day suppressive test in the $P$. berghei-infected mouse model [10]. Mice infected with the $P$. berghei NK 65 strain served as the reservoir, parasites were maintained by serial blood passage in mice, and the blood stage was stored at $-80^{\circ} \mathrm{C}$ until use. The donor mice were infected with $200 \mu \mathrm{l}$ of $P$. berghei parasite inoculum. The parasitized blood of each donor mouse was collected from the tail vein and diluted with $0.9 \%$ sodium chloride. ICR mice of both sexes were divided into five groups and each intraperitoneally infected with $0.2 \mathrm{ml}$ of saline suspension containing $1.0 \times 10^{7}$ parasitized erythrocytes (day 0). Three hours after infection, the mice in each group $(n=6)$ were treated with oral daily doses of $50,100,300$, or $600 \mathrm{mg} / \mathrm{kg}$ body weight of MEE for four consecutive days (test groups 1, 2, 3, and 4, respectively). Positive and negative control groups were treated daily with an oral daily dose of artesunate at $2 \mathrm{mg} / \mathrm{kg}$ body weight and $5 \%$ sodium carboxymethylcellulose, respectively. The parasitemia of each mouse was determined under light microscope by examination of Giemsa-stained thin blood smears prepared from the mouse tail 4 days (96 hours) post infection [11].

2.8. Antiplasmodial Curative Test. In this study, the antiplasmodial curative activity of the methanolic extract of Murraya exotica was investigated using the Ryley and Peters method [12]. Thirty-five (35) mice (18-25 g) were inoculated intraperitoneally with $1.0 \times 10^{7}$ cells $/ \mathrm{mm}^{3}$ of Plasmodium berghei NK 65 parasite. Parasitemia was confirmed after 72 hours, and the mice were randomly divided into 6 groups of 5 mice per group. Groups 5 and 6 served as the positive and negative 
controls, respectively. The positive control group was treated with artesunate $2 \mathrm{mg} / \mathrm{kg}$ orally, and an equivalent volume of $5 \%$ sodium carboxymethylcellulose was given to the negative control group. Groups 1, 2, 3, and 4 were treated with $50 \mathrm{mg} / \mathrm{kg}, 100 \mathrm{mg} / \mathrm{kg}, 300 \mathrm{mg} / \mathrm{kg}$, and $600 \mathrm{mg} / \mathrm{kg}$ of the plant extract, respectively. The treatment was daily for 5 days, and the oral route was used in each group. Blood samples were taken from the tail vein of each mouse onto a microscope slide to make thin films [13]. Blood smears were taken on days 1,3 , and 6 of drug treatment. The thin films were prepared by fixing the blood on the slide with methanol, then staining the slide with $10 \%$ Giemsa for 10 minutes. The thin films prepared were examined microscopically in order to establish the level of parasitemia.

The mean parasitemia in each group of mice for both the curative and the suppressive test was used to calculate the \% suppression for each dose using the following formula:

$$
\% \text { parasitemia }=\frac{\text { Number of parasitized RBCs }}{\text { Total number of RBCs counted }} \times 100 .
$$

Average percentage chemosuppression was calculated as

$$
\% \text { suppression }=\frac{\text { \%parasitemia in the negative control }-\% \text { parasitemia in the test }}{\% \text { parasitemia in the negative control }} \times 100
$$

2.9. Antipyretic Test. The effect of drugs on baker's yeastinduced hyperthermia as described by Tomazetti et al. [14] and Boakye-Gyasi et al. [15] was employed. A 2-day habituation session was conducted where rectal temperatures $\left(T_{R}\right)$ of the rats were recorded by inserting a lubricated digital thermometer (external diameter: $3 \mathrm{~mm}, 0.1^{\circ} \mathrm{C}$ precision) $3 \mathrm{~cm}$ into the rectum of rats. Rats with initial rectal temperature $\left(T_{R}\right)$ between 36 and $37^{\circ} \mathrm{C}$ were selected for these antipyretic tests. A pyogenic dose of baker's yeast $(0.135 \mathrm{~g} / \mathrm{kg}$, i.p.) was injected in each animal on the third day after measuring basal temperatures. Changes in rectal temperature $\left(T_{R}\right)$ were recorded every hour up to $4 \mathrm{~h}$. Rats with a rise of not less than $0.5^{\circ} \mathrm{C}$ in rectal temperature were selected for the experiment. Animals were randomly divided into six groups of five rats each. Group 1 received paracetamol ( $150 \mathrm{mg} / \mathrm{kg}$, p.o.). Groups 2, 3, 4, and 5 received MEE 50, 100, 300, and $600 \mathrm{mg} / \mathrm{kg}$, p.o., respectively. Group $6 \mathrm{did}$ not receive any drug/extract after the yeast administration. Another group of 5 rats (Group 7) received only normal saline $(0.9 \% \mathrm{NaCl}$, i.p.) without baker's yeast administration. $T_{R}$ were monitored hourly over the following $4 \mathrm{~h}$ period after extract/drug administration.

2.10. Subacute Toxicity Test. The oral subacute toxicity study of Murraya exotica methanolic leaf extract was carried out in Sprague-Dawley rats using the modified Locke test [16]. Sprague-Dawley rats, weighing $125-167 \mathrm{~g}$ were placed in 5 treatment groups. The negative control group (group 5) received normal saline. Various test groups of Murraya exotica were groups $1,2,3$, and 4 which received doses of 100 , 250, 500, and $1000 \mathrm{mg} / \mathrm{kg}$, p.o., respectively. The rats were observed for weakness, stimulation, anorexia, sleep, coma, and death in the first five hours and subsequently for 14 days. The variations in weights on day 1 , day 7 , and day 14 were as well investigated by taking the animals' weights on a balance on those days. On day 15, the rats were sacrificed by cervical dislocation, the jugular vein cut, and blood allowed to flow freely into tubes with and without ethylenediaminetetraacetic acid (EDTA) as coagulant. They were dissected, and their organs (lungs, liver, heart, and spleen) were weighed individ- ually. The organs were preserved thereafter in $10 \%$ formalin. The blood samples of the animals were as well collected in EDTA and plain tubes for hematological and biochemical analyses, respectively.

2.11. Hematological Parameters. Twenty-four hours after the last dose, the animals were sacrificed by cervical dislocation and the blood samples were collected by cardiac puncture. The blood samples for hematological parameters (white blood cell count, red blood cell count, hemoglobin, platelet count, and packed cell volume) were collected into EDTA containers and analyzed using an automated machine (Automated CBC Analyzer: Sysmex KX-21).

2.12. Biochemical Analysis. The blood samples for biochemical parameters (globulin, albumin, alkaline phosphatase, indirect bilirubin, direct bilirubin, total bilirubin, aspartate transaminase, alanine transaminase, gamma-glutamyl transpeptidase, urea, and creatinine) were collected into EDTA tubes and analyzed using an automated analyzer (automated biochemical analyzer).

2.13. Ethical Consideration. The use and handling of animals were in agreement with the National Institutes of Health Guidelines for Care and Use of Laboratory Animals (1985) and was approved by the Institutional Ethical Review committee of the Department of Pharmacology, Kwame Nkrumah University of Science and Technology (KNUST) (No. PHARM/ETHIC/ET194/19).

2.14. Statistical Evaluation. The statistical analysis of data obtained was analyzed using GraphPad V6.0 (GraphPad Prism software, San Diego, USA). The treatment groups and the controls were analyzed and compared using the one-way analysis of variance (ANOVA). The results obtained were expressed as mean \pm SEM. The antimalarial activity of MEE was determined from the ratio of percentage of parasite reduction in treated and negative control groups. 


\section{Results}

3.1. Phytochemical Screening. The preliminary phytochemical screening of the dried methanolic leaf extract of Murraya exotica showed the presence of tannins, saponins, coumarins, alkaloids, flavonoids, glycosides, and sterols. Table 1 shows the results of the phytochemical screening.

\subsection{Antiplasmodial Studies}

3.2.1. Rane/Curative Test. ICR mice were treated with $50 \mathrm{mg} / \mathrm{kg}, 100 \mathrm{mg} / \mathrm{kg}, 300 \mathrm{mg} / \mathrm{kg}$, and $600 \mathrm{mg} / \mathrm{kg}$ of Murraya exotica extract and $2 \mathrm{mg} / \mathrm{kg}$ of artesunate (positive control). After day 3 and day 6 of treatment, the positive control (artesunate $2 \mathrm{mg} / \mathrm{kg}$ ) showed the highest percentage suppression of $57.02 \pm 0.33$ and $89.13 \pm 0.0$, respectively. Murraya exotica also showed a significant decrease in the parasitemia after day 3 which further decreased on the $6^{\text {th }}$ day. The highest dose of Murraya exotica extract administered $(600 \mathrm{mg} / \mathrm{kg}$ ) showed the highest parasitemia suppression (64.61\%). Table 2 shows the results obtained from the antimalarial study.

3.3. Peters 4-Day Suppressive Test. In vivo 4-day suppressive assay results for the leaf extract of Murraya exotica using Plasmodium berghei-infected mice are summarized in Table 3. 96 hour postinfection, MEE at doses of $50 \mathrm{mg} / \mathrm{kg}$, $100 \mathrm{mg} / \mathrm{kg}, 300 \mathrm{mg} / \mathrm{kg}$, and $600 \mathrm{mg} / \mathrm{kg}$ showed a percentage suppression of $61.55 \pm 1.87,69.20 \pm 1.73,72.42 \pm 1.55$, and $76.02 \pm 1.38$, respectively. The positive control (artesunate, $2 \mathrm{mg} / \mathrm{kg}$ ) assayed in parallel reduced parasitemia by $82.56 \pm$ $0.97 \%$ with no observed mortality in the group after 30 days.

3.4. Antipyretic Activity. MEE at all doses reduced pyrexia in the Sprague-Dawley rats. The inhibition remained significant up to $4 \mathrm{~h}$ of administration. MEE at $100 \mathrm{mg} / \mathrm{kg}$ dose showed the maximum antipyretic effect and returned the body temperature to normal levels $(p>0.05)$, almost as effective as the standard drug paracetamol (Figure 1).

3.5. Subacute Toxicity. The subacute toxicity study revealed that the methanolic extract of Murraya exotica was safe up to $1000 \mathrm{mg} / \mathrm{kg}$.

3.6. Relative Organ Weight. With regard to the relative organ weight, it was observed that the target organs, heart, kidney, liver, and spleen, of the Sprague-Dawley rats in the test groups did not differ significantly from those of the control group as shown in Table 4.

3.7. Hematological Analysis. In the hematological screening, the following blood parameters assessed, red blood cell count, platelet count, white blood cell count, hemoglobin level, and cell volume, revealed that the methanolic extract of Murraya exotica at doses $100 \mathrm{mg} / \mathrm{kg}, 250 \mathrm{mg} / \mathrm{kg}, 500 \mathrm{mg} / \mathrm{kg}$, and $1000 \mathrm{mg} / \mathrm{kg}$ did not produce any significant effects when compared to the control. Table 5 shows the results obtained from the hematological analysis.

3.8. Biochemical Analysis. In the biochemical analysis, the various parameters assessed revealed that the methanolic
TABle 1: Secondary metabolized in the leaves of Murraya exotica (L.).

\begin{tabular}{lc}
\hline Secondary metabolite & Presence \\
\hline Tannins & + \\
Saponins & + \\
Coumarins & + \\
Alkaloids & + \\
Flavonoids & + \\
Glycosides & + \\
Sterols & + \\
\hline
\end{tabular}

Key: +: represents present.

TABle 2: Percentage suppression of Plasmodium berghei by four dose points of Murraya exotica and artesunate $(2 \mathrm{mg} / \mathrm{kg})$ on day 3 and day 6 , respectively.

\begin{tabular}{lcc}
\hline Treatment & Day 3 (\%) & Day 6 (\%) \\
\hline Group 1 $(50 \mathrm{mg} / \mathrm{kg})$ & $20.60 \pm 0.33$ & $45.84 \pm 0.00$ \\
Group 2 $(100 \mathrm{mg} / \mathrm{kg})$ & $33.67 \pm 2.23$ & $64.32 \pm 0.33$ \\
Group 3 $(300 \mathrm{mg} / \mathrm{kg})$ & $19.91 \pm 0.67$ & $56.74 \pm 2.16$ \\
Group 4 $(600 \mathrm{mg} / \mathrm{kg})$ & $26.19 \pm 0.00$ & $64.61 \pm 0.67$ \\
Positive control $(2 \mathrm{mg} / \mathrm{kg})$ & $57.02 \pm 0.33$ & $89.13 \pm 0.00$ \\
\hline
\end{tabular}

Values expressed as means \pm SEM $(n=5)$, compared to the control by Dunnett's multiple comparison test.

TABle 3: Percentage suppression of Plasmodium berghei by four dose points of Murraya exotica and artesunate $(2 \mathrm{mg} / \mathrm{kg})$ on day 4 .

\begin{tabular}{lc}
\hline Treatment & \% suppression \\
\hline Group 1 $(50 \mathrm{mg} / \mathrm{kg})$ & $61.55 \pm 1.87$ \\
Group 2 $(100 \mathrm{mg} / \mathrm{kg})$ & $69.20 \pm 1.73$ \\
Group $3(300 \mathrm{mg} / \mathrm{kg})$ & $72.42 \pm 1.55$ \\
Group 4 $(600 \mathrm{mg} / \mathrm{kg})$ & $76.02 \pm 1.38$ \\
Positive control $(2 \mathrm{mg} / \mathrm{kg})$ & $82.56 \pm 0.97$ \\
\hline
\end{tabular}

Values expressed as means $\pm \operatorname{SEM}(n=5)$, compared to the control by Dunnett's multiple comparison test.

extract of Murraya exotica at doses $100 \mathrm{mg} / \mathrm{kg}, 250 \mathrm{mg} / \mathrm{kg}$, $500 \mathrm{mg} / \mathrm{kg}$, and $100 \mathrm{mg} / \mathrm{kg}$ did not produce any significant effects on the test groups in comparison to the control group. Table 6 shows the results obtained from the biochemical analysis.

\section{Discussion}

The development of resistance to the commonly used antimalarial drugs and its resultant increase in morbidity and mortality due to malaria continue to pose a major public health threat [17]. To address this global threat caused by Plasmodium falciparum malaria, novel antimalarial drugs and potent vaccines are urgently needed. Murraya exotica grows widely in southern Asia, and it is used as an ornamental and hedge plant for its pleasant smell and beauty. However, the leaves and roots of the plant have been 


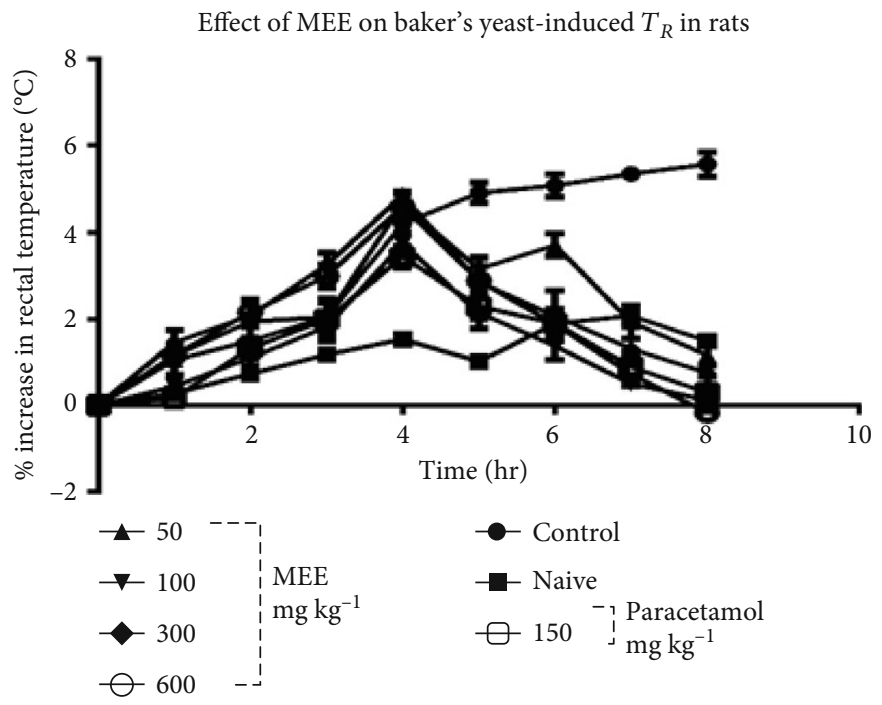

(a) Effect of MEE on baker's yeast-induced $T_{R}$ in rats

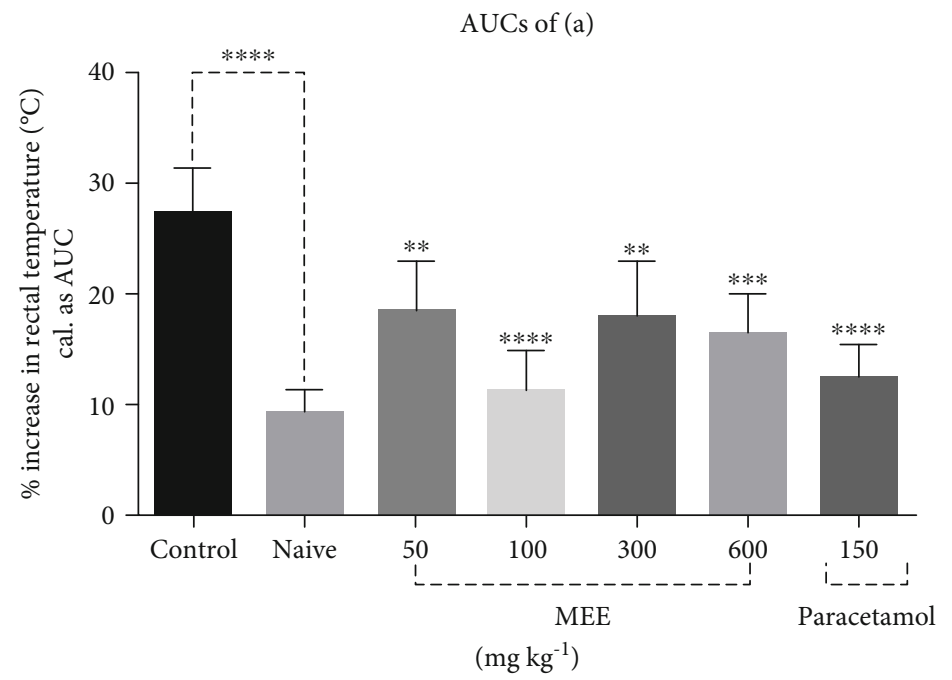

(b) AUCs of (a)

Figure 1: Effect of MEE 50-600 mg/kg, p.o., and paracetamol (150 mg/kg, p.o.) on time-course curve (a) and the total increase in temperature (calculated as AUCs (b)) on baker's yeast-induced changes of rectal temperatures in rats. Naive represents animals with no treatment with yeast. Values are expressed as mean $\pm \operatorname{SEM}(n=5) .{ }^{* * * *} p<0.001$ compared to vehicle-treated group (control) (ordinary one-way ANOVA comparison test with descriptive statistics).

TABLE 4: Effect of the methanolic extract of Murraya exotica on organ weights of rats treated for 14 days.

\begin{tabular}{|c|c|c|c|c|c|}
\hline \multirow[t]{2}{*}{ Organ } & \multirow[b]{2}{*}{ Control } & \multirow[b]{2}{*}{$100 \mathrm{mg} / \mathrm{kg}$} & \multicolumn{3}{|c|}{ Relative organ weight } \\
\hline & & & $250 \mathrm{mg} / \mathrm{kg}$ & $500 \mathrm{mg} / \mathrm{kg}$ & $1000 \mathrm{mg} / \mathrm{kg}$ \\
\hline Liver & $2.87 \pm 0.04$ & $3.40 \pm 0.30$ & $3.03 \pm 0.14$ & $3.33 \pm 0.19$ & $2.94 \pm 0.08$ \\
\hline Kidneys & $0.50 \pm 0.04$ & $0.61 \pm 0.04$ & $0.62 \pm 0.02$ & $0.64 \pm 0.02$ & $0.58 \pm 0.06$ \\
\hline Spleen & $0.38 \pm 0.08$ & $0.47 \pm 0.03$ & $0.46 \pm 0.08$ & $0.50 \pm 0.10$ & $0.45 \pm 0.02$ \\
\hline Heart & $0.41 \pm 0.07$ & $0.37 \pm 0.03$ & $0.39 \pm 0.01$ & $0.40 \pm 0.02$ & $0.41 \pm 0.02$ \\
\hline
\end{tabular}

Values are expressed as mean $\pm \operatorname{SEM}(n=5)$ compared to the control by the Newman-Keuls test.

traditionally used as medicine to treat rheumatalgia, toothache, malaria, and body pains from injury and trauma [6, 18]. In this study, the in vivo antiplasmodial and antipyretic activity and the safety profile of the methanolic leaf extract of the plant were assessed.
Phytochemical analysis showed that the Murraya exotica extract contains tannins, saponins, coumarins, alkaloids, flavonoids, glycosides, and sterols. Other studies performed also show that Murraya exotica extracts contain carbohydrates, proteins, amino acids, and phenolic compounds 
TABLE 5: Effects of the methanolic extract of Murraya exotica on the hematological parameters of Sprague-Dawley rats treated with the aqueous extract for 14 days.

\begin{tabular}{|c|c|c|c|c|c|}
\hline Parameters & Control & $100 \mathrm{mg} / \mathrm{kg}$ & $250 \mathrm{mg} / \mathrm{kg}$ & $500 \mathrm{mg} / \mathrm{kg}$ & $1000 \mathrm{mg} / \mathrm{kg}$ \\
\hline $\mathrm{RBC}$ & $8.06 \pm 0.44$ & $7.43 \pm 0.7$ & $7.38 \pm 0.17$ & $7.37 \pm 0.1$ & $8.16 \pm 0.67$ \\
\hline HGB & $14.13 \pm 0.57$ & $13.43 \pm 0.53$ & $13.5 \pm 0.46$ & $12.9 \pm 0.4$ & $13.87 \pm 0.74$ \\
\hline $\mathrm{HCT}$ & $52.97 \pm 3.6$ & $49.87 \pm 2.12$ & $49.13 \pm 1.84$ & $48.43 \pm 1.13$ & $49.9 \pm 2.7$ \\
\hline $\mathrm{MCV}$ & $65.6 \pm 1.35$ & $67.8 \pm 3.67$ & $66.6 \pm 2.13$ & $65.7 \pm 0.3$ & $61.43 \pm 1.89$ \\
\hline $\mathrm{MCH}$ & $17.6 \pm 0.32$ & $18.27 \pm 1.01$ & $18.3 \pm 0.5$ & $17.5 \pm 0.1$ & $17.1 \pm 0.78$ \\
\hline $\mathrm{MCHC}$ & $26.8 \pm 1.01$ & $26.93 \pm 0.09$ & $27.47 \pm 0.12$ & $26.6 \pm 0.21$ & $27.8 \pm 0.5$ \\
\hline PLT & $507 \pm 162.7$ & $754.33 \pm 52.3$ & $821 \pm 79.04$ & $910.33 \pm 170.04$ & $768.33 \pm 6.55$ \\
\hline WBC & $11.37 \pm 2.72$ & $11.13 \pm 2.28$ & $7.67 \pm 0.64$ & $9.23 \pm 0.68$ & $9.47 \pm 0.62$ \\
\hline LYM & $75.1 \pm 7.03$ & $80.27 \pm 5.09$ & $73.17 \pm 3.9$ & $72.3 \pm 6.07$ & $61.33 \pm 7.41$ \\
\hline NEUT & $24.9 \pm 7.03$ & $25.27 \pm 5.10$ & $30.25 \pm 2.65$ & $31.7 \pm 6.45$ & $41.65 \pm 9.59$ \\
\hline
\end{tabular}

Values expressed as means \pm SEM $(n=3)$, compared to the control by Dunnett's multiple comparisons test.

TABLE 6: Effects of the methanolic extract of Murraya exotica on the biochemical parameters of Sprague-Dawley rats after 14 days of treatment.

\begin{tabular}{|c|c|c|c|c|c|}
\hline Parameters & Control & $100 \mathrm{mg} / \mathrm{kg}$ & $250 \mathrm{mg} / \mathrm{kg}$ & $500 \mathrm{mg} / \mathrm{kg}$ & $1000 \mathrm{mg} / \mathrm{kg}$ \\
\hline ALB & $36.33 \pm 0.88$ & $36.33 \pm 1.20$ & $36.67 \pm 1.86$ & $37.00 \pm 0.58$ & $35.67 \pm 0.33$ \\
\hline GLB & $45+1.0$ & $46.00 \pm 0.58$ & $49.67 \pm 3.35$ & $48.33 \pm 0.67$ & $47.00 \pm 2.52$ \\
\hline T.PRO & $81.33 \pm 1.76$ & $82.33 \pm 0.88$ & $79.67 \pm 3.33$ & $85.33 \pm 0.33$ & $82.67 \pm 2.67$ \\
\hline ALP & $719 \pm 42.17$ & $688.33 \pm 103.65$ & $796.7 \pm 3.39$ & $692.33 \pm 60.4$ & $797.00 \pm 71.85$ \\
\hline ALT & $215.33 \pm 13.44$ & $216.33 \pm 12.67$ & $194.33 \pm 22.82$ & $231.17 \pm 36.1$ & $212.67 \pm 17.05$ \\
\hline AST & $17.67 \pm 11.72$ & $23.67 \pm 2.60$ & $54.33 \pm 10.93$ & $56.00 \pm 39.96$ & $61.67 \pm 40.68$ \\
\hline D.BIL & $1.67 \pm 0.33$ & $2.00 \pm 0.00$ & $1.82 \pm 3.37$ & $1.67 \pm 0.33$ & $2 \pm 0$ \\
\hline IND.BIL & $1 \pm 0$ & $1.00 \pm 0.00$ & $1.02 \pm 3.38$ & $0.33 \pm 0.33$ & $0.33 \pm 0.33$ \\
\hline T.BIL & $2.67 \pm 0.33$ & $3.00 \pm 0.00$ & $2.84 \pm 3.36$ & $2 \pm 0$ & $2.33 \pm 0.33$ \\
\hline GGT & $0.33 \pm 0.33$ & $2.33 \pm 4.33$ & $0.33 \pm 0.67$ & $0.54 \pm 0.33$ & $0.67 \pm 0.67$ \\
\hline
\end{tabular}

Values expressed as means \pm SEM $(n=3)$, compared to the control by Dunnett's multiple comparison test. ALB: albumin; GLB: globulin; T.PRO: total protein; ALP: alkaline phosphatase; ALT: alanine transaminase; AST: aspartate transaminase; D.BIL: direct bilirubin; IND.BIL: indirect bilirubin; T.BIL: total bilirubin; GGT: gamma-glutamyl transferase.

[19], phytosterol and coumarins [20], alkaloids and flavonoids [21], and flavone derivatives [22]. These compounds may be responsible for the biological activity of the plant. A compound isolated from Murraya exotica, umbelliferone, was reported to have antihyperlipidemic and antidiabetic activities [23]. The similarity in the phytochemicals reported with earlier studies confirms the identity of the plant used in the biological assays.

Subacute toxicity studies are important to establish the safe use of plant products for human use. Analyses of hematological and biochemical parameters, and relative organ weight present an effective measure of assessing the safety profile of a drug or plant product. The 14-day subacute toxicity study in rat showed no signs of toxicity, behavioral changes, and mortality when methanolic extracts of Murraya exotica up to $1000 \mathrm{mg} / \mathrm{kg}$ were administered compared to the control groups.

In toxicology studies, comparison of organ weights between treated and untreated groups of animals is used con- ventionally to evaluate the toxic effect of the test substance [24]. The usefulness of relative organ weight in toxicity studies includes sensitivity to predict toxicity, enzyme induction, physiologic perturbations, and acute injury; it correlates well with histopathological changes, and there is little interanimal variability [25]. There were no significant differences in the weights of the target organs of the treatment groups when compared to the control group (Table 4). This indicates that the methanolic extract Murraya exotica treatment for 14 days did not cause any detrimental effect on the heart, kidney, liver, and spleen of the Sprague-Dawley rats in the various treatment groups.

Most toxic compounds target the hematopoietic system, an important index of physiology, and hence help to determine the pathological status in man and animals [26]. In the hematological analysis, the values of the different parameters assessed [red blood cell (RBC), hemoglobin (Hb), hematocrit (HCT), white blood cell (WBC), mean cell hemoglobin $(\mathrm{MCH})$, mean cell hemoglobin concentration 
(MCHC), and platelet] for the treated groups were within normal biological and laboratory limits when compared with the values of the control group. No significant changes were observed in all the treated groups as compared to the control groups. This indicates that the Murraya exotica extract does not show significant adverse effects on the blood, blood cells, and target organs at the doses used. In the biochemical assays, there was no significant increase in the levels of the parameters measured at different doses (Table 6) in the different groups of animals treated with the extract as compared to the control. Murraya exotica extract at different dose levels (up to $1000 \mathrm{mg} / \mathrm{kg}$ ) tested did not produce considerable change in the levels of the different parameters measured accounting for the safety of the plant in human use.

The in vivo curative antiplasmodial study showed that the plant extract demonstrated antimalarial activity with the highest percentage of parasitemia suppression exerted by group 4 (64.61), that is, mice receiving the highest dose of $600 \mathrm{mg} / \mathrm{kg}$ of the Murraya exotica extract. The positive control group receiving artesunate $2 \mathrm{mg} / \mathrm{kg}$ exerted $89 \%$ suppression. The rise in percentage suppression observed in the various groups was not in proportion to the dose administered. Group 2 (100 mg/kg MEE) for instance recorded a percentage suppression of 33.67 on day 3 and 64.32 on day 6 whereas group $3(300 \mathrm{mg} / \mathrm{kg}$ MEE) with a higher dose recorded a percentage suppression of 19.91 and 56.74 on days 3 and 6 , respectively. In the 4-day suppressive antiplasmodial assay, MEE produced a dose-dependent chemosuppression, with the lowest dose tested $(50 \mathrm{mg} / \mathrm{kg}$ ) producing significant reduction in parasitemia $(61.55 \%)$. The highest dose of MEE tested $(600 \mathrm{mg} / \mathrm{kg})$ in group $4 \mathrm{had}$ a percentage suppression of $76.02 \%$ and did not achieve the level of chemosuppression seen with the positive control-artesunate $(2 \mathrm{mg} / \mathrm{kg})$ which had a suppression of $82.56 \%$ on the $5^{\text {th }}$ day. The results indicate that the methanolic leaf extract of Murraya exotica possesses both suppressive and curative antiplasmodial activity at the doses tested.

MEE at all doses $(50,100,300$, and $600 \mathrm{mg} / \mathrm{kg}$ ) reduced the baker's yeast-induced pyrexia in the Sprague-Dawley rats. These inhibitions remained significant up to $4 \mathrm{~h}$ of administration. MEE at $100 \mathrm{mg} / \mathrm{kg}$ showed the maximum antipyretic effect and returned body temperature to normal levels $(p>0.05)$, almost as effective as the standard drug paracetamol at $150 \mathrm{mg} / \mathrm{kg}$.

The antipyretic effects of MEE observed might be due to possible reduction in the brain concentration of prostaglandin $\mathrm{E}_{2}$ especially in the hypothalamus through its action on COX-3 or by the enhancement of the production of the body's own antipyretic substances like vasopressin and arginine by pharmacologically active metabolites. These antipyretic substances are known to reduce proinflammatory mediators, improve anti-inflammatory signals at sites of injury, or increase antipyretic messages within the brain [27].

A secondary plant metabolite such as alkaloids, quassinoids, and sesquiterpene lactones has been shown to possess antimalarial activity [28]. The phytochemical screening of the dried methanolic leaf extract of Murraya exotica showed the presence of tannins, saponins, coumarins, alkaloids, flavonoids, glycosides, and sterols. Although the active constit- uents in the plant extract responsible for the antimalarial effects are not known or have yet to be identified, the presence of alkaloids, glycosides, tannins, and flavonoids has been implicated in antipyretic and antiplasmodial activity and might be as a result of a single, additive, or synergistic action of these compounds $[29,30]$.

\section{Conclusion}

The findings in this study show that the methanolic extract of Murraya exotica is safe in Sprague-Dawley rats and demonstrate both suppressive and curative antiplasmodial activity in Plasmodium berghei-infected mice. MEE also possessed considerable antipyretic properties at the doses tested in the baker's yeast-induced pyrexia in rodent models. This study gives support to the claim for the traditional use of the plant in the treatment of malaria and fever.

\section{Data Availability}

All data generated or analyzed during this study are included in this published article.

\section{Ethical Approval}

The use and handling of animals was approved by the Institutional Ethical Review committee of the Department of Pharmacology, Kwame Nkrumah University of Science and Technology (KNUST) (No. PHARM/ETHIC/ET194/19).

\section{Conflicts of Interest}

The authors declare that they have no competing interests.

\section{Authors' Contributions}

$\mathrm{ADF}, \mathrm{EOA}$, and $\mathrm{KBM}$ conceived the research idea and designed the experiment; $\mathrm{NKKB}, \mathrm{ADF}, \mathrm{CA}$, and $\mathrm{AOA}$ performed the experiments and analyzed and interpreted the data as well as prepared the first draft of the paper. All authors read and approved the final manuscript.

\section{Acknowledgments}

We like to acknowledge all the Technicians in the Department of Pharmacology, KNUST.

\section{References}

[1] WHO: World malaria report, WHO Global Malaria Programme, World Health Organization, Geneva, 2017.

[2] N. J. White, “Twenty-second ed. Saunders," Manson's Tropical Diseases, G. C. Cook, P. Manson, and A. Zumla, Eds., pp. 1201-1300, 2009.

[3] B. T. Grimberg and R. K. Mehlotra, "Expanding the Antimalarial Drug Arsenal-Now, But How?," Pharmaceuticals, vol. 4, no. 5, pp. 681-712, 2011.

[4] C. Guinovart, J. J. Aponte, J. Sacarlal et al., "Insights into LongLasting Protection Induced by RTS,S/AS02A Malaria Vaccine: Further Results from a Phase IIb Trial in Mozambican Children," PLoS ONE, vol. 4, no. 4, p. e5165, 2009. 
[5] J. B. Harborne, "Pharmacognosy and Phytochemistry : edited by H. Wagner and L. Hörhammer. Springer-Verlag, Berlin, 1971. 386 pp. DM 48.00," Phytochemistry, vol. 11, no. 5, pp. 1869-1870, 1972.

[6] V. K. Singh and Z. A. Ali, "Folk medicines in primary healthcare: common plants used for the treatment of fevers in India," Fitoterapia, vol. 65, no. 1, pp. 68-74, 1994.

[7] China Pharmacopoeia Committee, "Pharmacopoeia - The Chinese Pharmacopoeia," in Pharmacopoeia of the People's Republic of China, Chinese Medical Science and Technology Press, Beijing, China, 2010.

[8] L. Wu, P. Li, X. Wang, Z. Zhuang, F. Farzaneh, and R. Xu, "Evaluation of anti-inflammatory and antinociceptive activities of Murraya exotica," Pharmaceutical Biology, vol. 48, no. 12, pp. 1344-1353, 2010.

[9] Y. Vaghasiya, R. Dave, and S. Chanda, "Phytochemical analysis of some medicinal plants from western region of India," Research Journal of Medicinal Plant 2011, vol. 5, no. 5, pp. 567-576.

[10] W. Peters, J. H. Portus, and B. L. Robinson, “The chemotherapy of rodent malaria, XXII," Annals of Tropical Medicine \& Parasitology, vol. 69, no. 2, pp. 155-171, 2016.

[11] C. O. Esume, J. O. T. Emudainohwo, A. O. Opajobi, I. M. Osifo, and U. R. Onyemekeih, "An investigation into the anti-malaria property of ethanolic extract of the leaves of Gongronema latifolium on artesunate sensitive $P$. berghei infected albino mice," Continental Journal of Tropical Medicine, vol. 5, pp. 10-14, 2011.

[12] J. F. Ryley and W. Peters, "The antimalarial activity of some quinolone esters," Annals of Tropical Medicine \& Parasitology, vol. 64, no. 2, pp. 209-222, 2016.

[13] K. Saidu, J. Onah, A. Orisadipe, A. Olusola, C. Wambebe, and K. Gamaniel, "Antiplasmodial, analgesic, and antiinflammatory activities of the aqueous extract of the stem bark of Erythrina senegalensis," Journal of Ethnopharmacology, vol. 71, no. 1-2, pp. 275-280, 2000.

[14] J. Tomazetti, D. S. Ávila, A. P. O. Ferreira et al., "Baker yeastinduced fever in young rats: characterization and validation of an animal model for antipyretics screening," Journal of Neuroscience Methods, vol. 147, no. 1, pp. 29-35, 2005.

[15] E. Boakye-Gyasi, G. K. Ainooson, and W. K. M. Abotsi, "Antiinflammatory, antipyretic and antioxidant properties of a hydroalcoholic leaf extract of Palisota hirsuta K. Schum. (Commelinaceae)," West African Journal of Pharmacy, vol. 22, no. 1, pp. 10-18, 2011.

[16] D. Lorke, "A new approach to practical acute toxicity testing," Archives of Toxicology, vol. 54, no. 4, pp. 275-287, 1983.

[17] K. Marsh, "Malaria disaster in Africa," Lancet, vol. 352, no. 9132, pp. 924-925, 1998.

[18] C. P. Committee, "Pharmacopoeia - The Chinese Pharmacopoeia," in Pharmacopoeia of the People's Republic of China, Chemical Industry Press, Beijing, 2005.

[19] M. K. Gautam, M. Gangwar, G. Nath, C. V. Rao, and R. K. Goel, "In-vitro antibacterial activity on human pathogens and total phenolic, flavonoid contents of Murraya paniculata Linn. leaves," Asian Pacific Journal of Tropical Biomedicine, vol. 2, no. 3, pp. S1660-S1663, 2012.

[20] C. Ito and H. Furukawa, "Constituents of Murraya exotica L. Structure elucidation of new coumarins," Chemical \& Pharmaceutical Bulletin, vol. 35, no. 10, pp. 4277-4285, 1987.
[21] N. Alithleen, "Bioactivity studies and chemical constituents of Murraya paniculata," International Food Research Journal, vol. 19, pp. 1307-1312, 2012.

[22] J. Zhang, J. Lu, Q. Zhang et al., "Simultaneous Screening and Identifying Four Categories of Particular Flavonoids in the Leaves of Murraya exotica L. by HPLC-DAD-ESI-MS-MS," Journal of Chromatographic Science, vol. 52, no. 2, pp. 103114, 2014.

[23] B. Ramesh and K. V. Pugalendi, "Antihyperlipidemic and antidiabetic effects of umbelliferone in streptozotocin diabetic rats," The Yale Journal of Biology and Medicine, vol. 78, no. 4, pp. 189-196, 2005.

[24] B. Michael, B. Yano, R. S. Sellers et al., "Evaluation of organ weights for Rodent and non-rodent toxicity studies: a review of regulatory guidelines and a survey of current practices," Toxicologic Pathology, vol. 35, no. 5, pp. 742-750, 2017.

[25] International Conference of Harmonization of Technical Requirements for Registration of pharmaceuticals for Human use (ICH) TOPIC S8, "Immunotoxicity studies for human pharmaceuticals," Notes for Guidance on Immunotoxicity Studies for Human Pharmaceuticals, 2006.

[26] J. T. Mukinda and J. A. Syce, "Acute and chronic toxicity of the aqueous extract of Artemisia afra in rodents," Journal of Ethnopharmacology, vol. 112, no. 1, pp. 138-144, 2007.

[27] A. S. Khan, "Antipyretic and analgesic activities of some economically important woody plants," in In Medicinally Important Trees, pp. 159-185, Springer, Cham, 2017.

[28] S. Saxena, N. Pant, D. C. Jain, and R. S. Bhakuni, "Antimalarial agents from plant sources," Current Science, vol. 85, pp. 1314$1329,2003$.

[29] D. E. Okwu and M. E. Okwu, "Chemical composition of Spondias mombin Linn plant parts," Journal of Sustainable Agriculture and Environment, vol. 6, no. 2, pp. 140-147, 2004.

[30] G. E. Trease and W. C. Evans, Pharmacognosy, Balliere Tindall, London, 1989. 